\title{
Wealth and Potentials as Motor for the Development of World Heritage Site of Preah Vihear and its Region in Cambodia
}

\author{
UK SOMETH* and Masaru MINAGAWA ** \\ * Department of Urban Heritage Development, APSARA National Authority, Siem Reap, CAMBODIA \\ ** Faculty of Engineering, Tokyo City University, 1-28-1 Tamazutsumi, Setagaya-ku, Tokyo 158-8557, JAPAN
}

\begin{abstract}
Preah Vihear in Cambodia is typically an isolated region that has been neglected for many decades. In 2008, when Preah Vihear was listed as World Heritage Site, the Cambodian government finally started to pay attention to this remote region. One of the most important issues is how Preah Vihear could be an economic and eco-cultural motor for the development in one of the poorest regions in the country. Preah Vihear can be an engine for the development of the region, if once its potentials of cultural heritage combine with its natural resources. This paper indicates that Preah Vihear and its region has various heritage values and regional cultural values, and its resources are able to generate development. These could lead to the road of sustainability, if once all the criteria for economic growth works well and the conditions for social progress are fulfilled. In that perspective, Preah Vihear must have a chance to achieve its final goal and reduce poverty gap by sustainable development.
\end{abstract}

Key words : World heritage site, cultural value, sustainable development, Preah Vihear

\section{INTRODUCTION}

Most of the development efforts by Cambodian governments in the last two decades have been concentrated in the central plain of the country. It is understandable and common to concentrate the economical efforts and social activities to the nation's capital. In many countries in the past, the governing power tends to do the same planning policy because they would rely on using the existing network of infrastructures and facilities to continue the development and to resist changes.

In this view, Cambodia is not an exception. Although it has wealth and potentials, Preah Vihear, shown by Fig.1, is typically an isolated region that has been neglected for many decades. In 2008, when Preah Vihear was listed as World Heritage Site, the Cambodian government finally started to pay attention to this remote region. The question is how Preah Vihear could be an economic and eco-cultural motor for the development in one of the poorest regions in the country.

The authors discussed the past development trends and the present issues, considering the requirements for the consistent strategy. We also examined what the future sustainable development should be for this valuable heritage region ${ }^{1)}$. In that study, we suggested that rediscovery of the potentials of Preah Vihear could lead the region up to better future, and concluded that concrete development activities should be done by sound strategy and long-term vision.

This article mainly deals with the potentials of Preah Vihear, analyzing various values the region contains. At first, we will discuss the historical heritage values from various viewpoints: geographical, religious, architectural and landscape values. After that, contemporary significance of regional culture will be discussed: archeological patrimony, nature, and immaterial property. Then, we conclude that complex type tourism can make Preah Vihear explore these possibilities. By doing so, the region plays a role as the motor of the economic growth and social improvement for the future. After all, we confirm that natural and human resources need to go through recycling concept in order to achieve sustainable development.

\section{WEALTH OF PREAH VIHEAR}

(1) Historical Heritage Value

a) Geographical Value

The region of Preah Vihear temple along with the Dangrek Mountain has a long and vibrant history. Rich and invaluable information makes Cambodia one of the oldest nations in South East Asia. The Foothills province of the Dangrek is an ancient area 
inhabited since pre-historic time ${ }^{3)}$. Research conducted at three sites in the region proves that this region is one of the earliest shelters of $\operatorname{man}^{3)}$.

The inscriptions from Prasat (temple) Neak Buos says that Dangrek was the starting point of the Khmer nation, suggesting that the region was already occupied in the pre-Angkor period ${ }^{3)}$.

Based on these findings, Preah Vihear could be correctly assessed in the geopolitical context of the Dangrek Range, where the sacred complex is located as a strategic point for further expansion of the Khmer Empire.

The existence of many Khmer temples at the Foothills province suggests that the region was densely populated and prosperous under the Angkor Empire. According to an archeological mapping at Arogyashala Community done by the Council of Ministers ${ }^{4)}$, there was a human settlement from that period which still shows its trace of the existing village called $\mathrm{Kol}^{6}$.

Research by a joint team of APSARA National Authority and Thai institutions proved that many industrial sites, such as iron smelting and ceramic production centers, existed in the Foothills province as shown by Fig.2. Based on the archeological researches and studies, the geographical location of the temples is rich in natural resources, especially in the water resource. On the other hand, the topography causes a difficulty by the Dangrek Range, a natural boundary marker. The limited access makes it difficult to move forward.

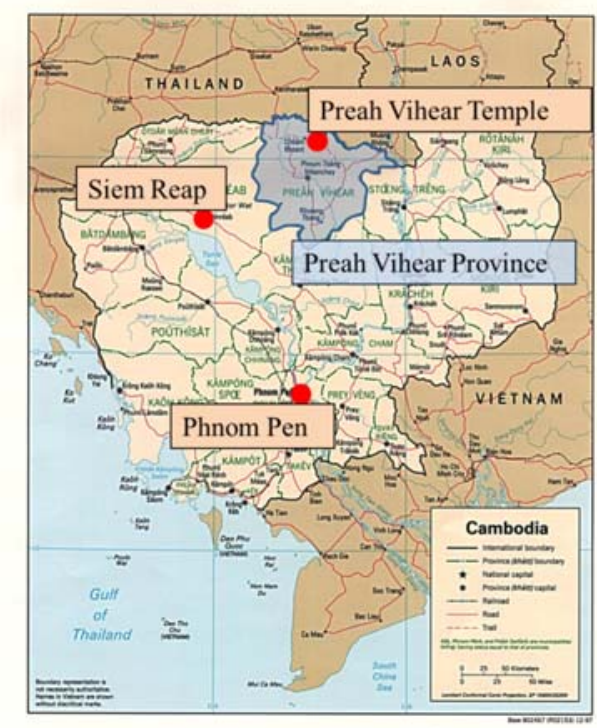

Fig. 1 Geographic position of Preah Vihear temple ${ }^{2)}$ ( The university of Texas Library, 1997)
As shown in Fig.3, however, this natural resource was coincident with the population density and the development of agriculture. After it rains on the Dangrek Mountain during monsoon season, the rainwater produces water streams downhill. Ancient man-made reservoirs called "Barays" were discovered on the foot of the mountain. The Barays were built in order to catch and store the rainwater running down from the top of the surrounding mountains. Such an accumulation of water favored economic and cultural activities in the Foothills province. It contributed to the political, economic, and cultural success of the Khmer Empire.

Along with industrial development such as iron, bronze and ceramic as shown in Fig4, the cultural and religious custom shown by Fig $\mathbf{5}$ reinforced in binding the economy

and the politics strong enough to ensure the sustainability of the Khmer Empire power from 12th to 15 th centuries.

\section{b) Religious Value}

All along the Dangrek Range, numerous temples were constructed practically on the similar style between 11th and 12th centuries. At the beginning, a cave was devoted to holy presence. It is still now a sacred place of religious worship as shown by Fig 5 .

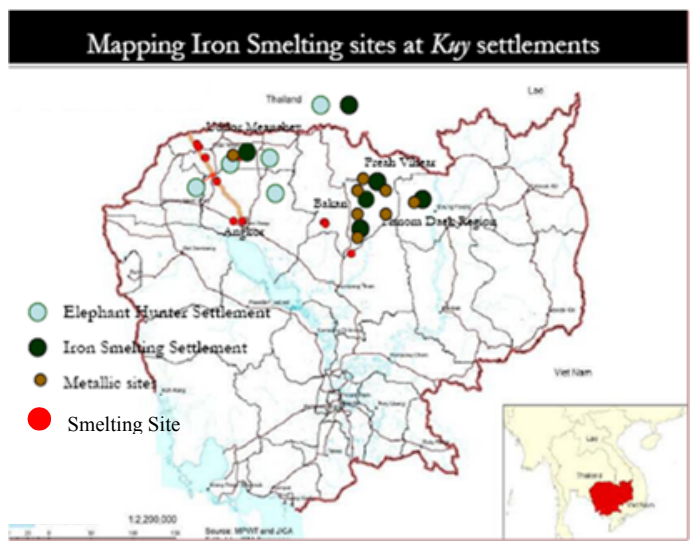

Fig.2 Economic activities in and around the Foothills province along the Dangrek Range during $10^{\text {th }}$ to $12^{\text {th }}$ centuries $^{5)}$

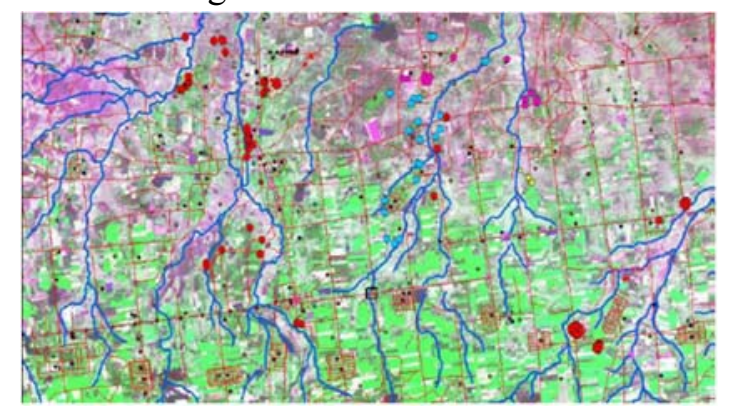

Fig 3 The water resource in the Foothills province ${ }^{5)}$ 


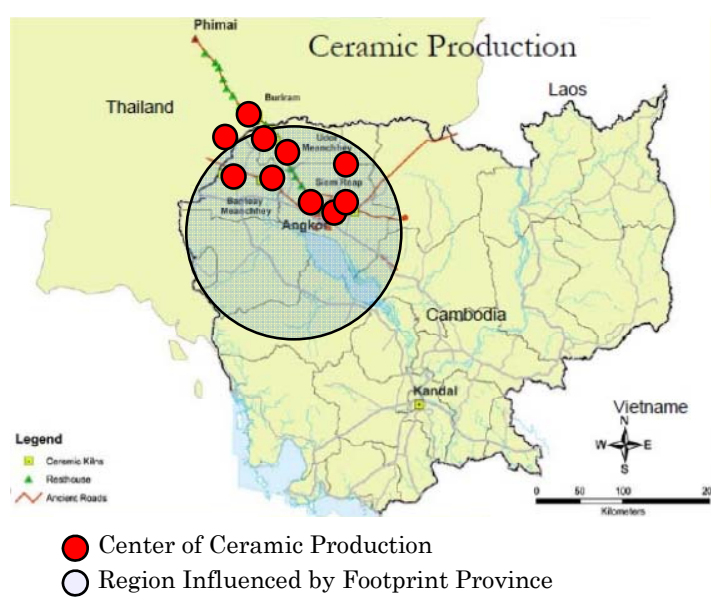

Fig 4 Ceramic production as industrial activity $^{5)}$

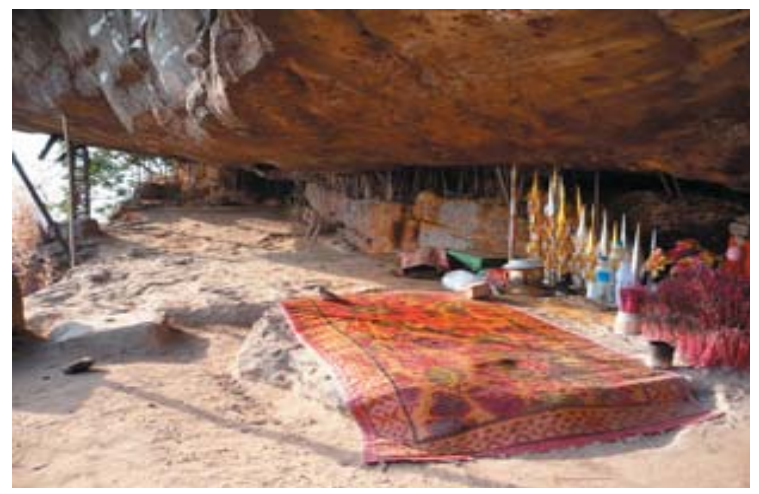

Fig.5 Cave as spiritual place in Preah Vihear Temple $^{7)}$

Then the later temples dedicated the relief of the footprints of Siva to the Cambodian kings, who have given royal patronage to them for the last four hundred years. The complex served as a place for pilgrimage, and also as a rallying point for a number of hermitages and temples spreading along the Foothills province. The hierarchy of worship and the geographical distribution of temples prove that Preah Vihear was the center of cultural and ritual networking in and beyond the region, and also the Foothills province must be the religious cultural heritage place during the Khmer Empire ${ }^{3)}$.

The most intriguing matter about the religious heritage is that these temples are finely conserved. In many historical cases, religions are often a cause of conflict when people share the same site and use the same place of worship. In the case of Preah Vihear, however, all along the centuries up to today, religions have cohabited without incident. The fundamental of religious spirit was so strong that this particular situation was created and became a heavenly place of mutual respect, tolerance and peace.

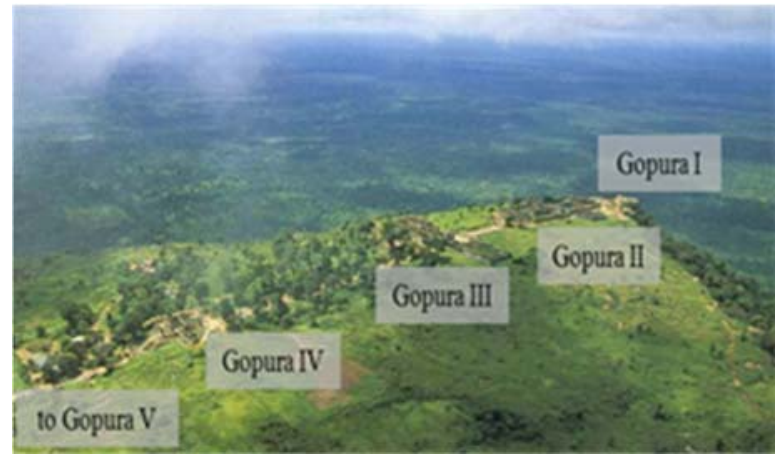

Fig.6 Architectural composition of Preah Vihear temple and its surrounding landscape

(Curtsey of PVNA)

These exceptional features come from ingenuity of the ancients in the Khmer nation. Their creation and artifact are outstanding in the domain of arts, architectural and engineering. Preah Vihear temple is an example of masterpiece by the ancestors and now attracts attention as one of the wonders of the Angkor civilization. The sacred site has been viewed through the context of its cultural geography because its own particularity makes it different from other Khmer temples.

Among many temples in various periods in the region, Preah Vihear is considered as the most important one. It stands out by its exceptional universal value, and emerges as an everlasting symbol of Khmer ancestors. They built and left heritage to their grandchildren of the future generation.

\section{c) Architectural Value}

Preah Vihear, like many other mountain peaks in the mainland of South-east Asia, is a place of pilgrimage and austere practices. Khmer ancestors concentrated all their efforts on how to move from the bottom to the top in order to get closer to the God Siva in the heaven ${ }^{3)}$. Based on this historical perspective, the architectural composition of Preah Vihear is interpreted on the descendant movement. Fig.6 shows the arrangement of the pavilions in the site. The pavilions (gates), which are called gopuras, are lined from the top down to below, so the highest pavilion is counted as pavilion I and the lowest one is as pavilion $\mathrm{V}$.

There are two ways to get to the sanctuary at the top. First one is a sequence of stairway-entrance pavilion, and the other is a series of gopuras. The design harmonizes with the natural environment. Three distinguished elements constitute the sacred 
components of the construction of the temple :

the courts, the stairways and the causeway connecting the gopuras. On the East side of the temple complex, there is the historic East Staircase, which is a combination of natural mountain rock cut into stone steps and man-made blocks of stone. The East Staircase of $1.4 \mathrm{~km}$ long, slowly rising up to the height of $650 \mathrm{~m}$, is another proof of Khmer ingenuity ${ }^{4}$.

\section{d) Value of Landscape}

Fig.6 shows another value of the site: the outstanding landscape. The setting of Preah Vihear, as part of the Dangrek mountains peak of $625 \mathrm{~m}$ high, with cloud floating in the air and the sky above, produces a breathtaking sensation. An impressive beautiful landscape is looking towards Cambodian forest and rice fields at a distance far beyond $10 \mathrm{~km}$ from the direction of World Heritage site of Angkor Thom, a city complex in the Khmer Empire and its most significant Temple Angkor Wat. In considering all the factors enumerated, it is precise to believe that the temple of Preah Vihear should be viewed not only as a rich cultural heritage, but also an invaluable asset as an economic capital. The richest natural elements are found on the top of the mountain range. They are free from human disturbances and followed with natural growth within the eco-system of the milieu.

Men in the region of Preah Vihear respect its natural environment and have been continuing for centuries without drastic changes or brutal transformation of natural milieu. The process of symbiosis between men and nature has still kept a good balance. Although the cycle of eco-system has not yet been disrupted, the disequilibrium of the whole mechanism for natural cycling could be in danger soon without the protection program for species.

The architectural design of the Preah Vihear was completed under careful selection of surrounding landscape. The architecture is one of the masterpieces of Khmer monuments by Cambodians architects and engineers. The first component of landscape is of natural environment provided by the local climate, vegetation and the topography of the region. The second element is the ingenuity of Khmer builders to use and manage the local material to produce artificial landscape. Actually, the materials for the construction of the temple were mainly of the stone quarried on the site. It is also remarkable with its abstract sculpture. In that context, the Preah Vihear temple is a good example of an outstanding architectural achievement among many other Cambodian monuments during the Khmer Empire.

\section{(2) Regional Cultural Value}

\section{a) Archeological Patrimony Value}

Cambodia is rich in archeological sites. There are more than 4,000 ancient temples scattered throughout the country sites, as shown by Fig.7. These temples and archeological sites constitute the second phase of the development of the Khmer history that led to the apex of the Khmer Empire during Angkor period. This richness is one of the basic components of cultural wealth that marks the civilization of the Khmer nation through many centuries from the Kouk Thlok era up to the fall of Angkor. In this respect, the region of Preah Vihear is part of the global archeological patrimony in the country. It is considered as valuable cultural assets

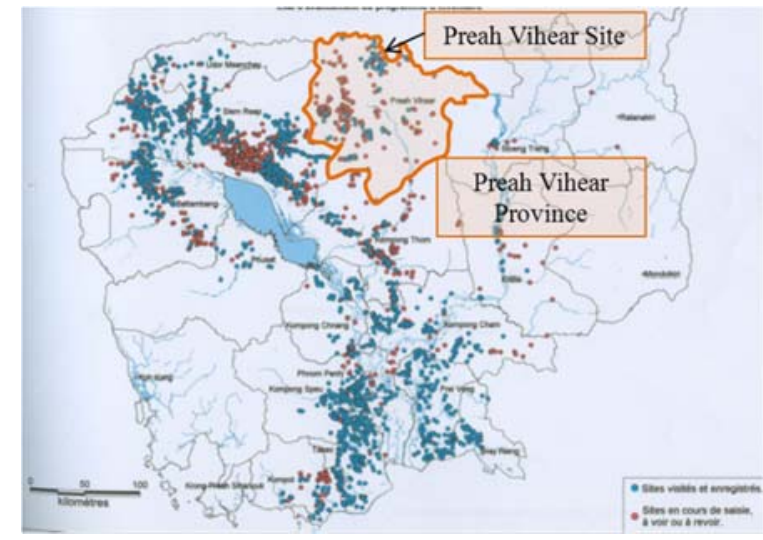

Fig.7 Major Archeological sites in Cambodia Preah Vihear Region ${ }^{8)}$

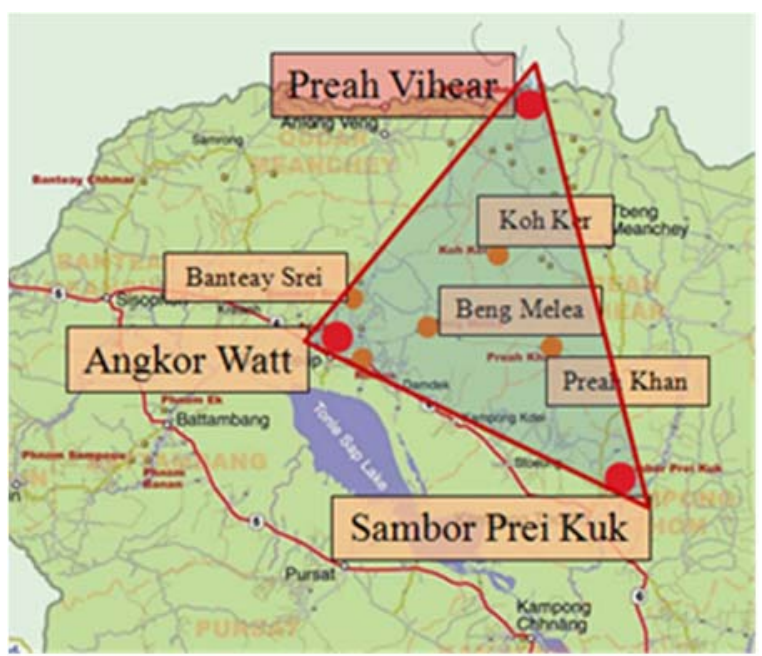

Fig.8 Preah Vihear Region linking to the Khmer empire major archeological sites ${ }^{5)}$ 
that could be transformed into utilizations of resources. As shown in Fig.8, Preah Vihear region in terms of archeological value is linked into the network of the overall cultural sites in the country that makes Cambodia one of the richest cultural heritages in the world.

\section{b) Value of Nature}

Nature has been always an integrated element in the architectural composition of Khmer monument. Preah Vihear happens to be located in an area rich of nature. The geographical setting is the first basic element in the design process. The Dangrek Mountain range being high up into the sky gives the site a particular feature, which stands up like a great barrier surrounding by vast plain. It is significant in terms of landscaping.

Because of its unique position among the other central provinces and the undeveloped state, Preah Vihear has a low density of 12.4 inhabitant per $\mathrm{km}^{2}$ in 20089). The density is getting lower in the Preah Vihear temple area. The density is less than 10 inhabitants per $\mathrm{km}^{2}$, and gets down to $94 \%$ of rural population.

In this case, land is also a potential if properly managed. It provides agricultural production enough to feed the poor people in the region so at least they can have a food safety net. But this is far from reality. Substantially available cultivated areas are given for concessions to private sectors, which leads to encroachment on farmers' rice fields, creation of a serious pressure for the farmers and pressure to a land dispute. To avoid the depletion of agrucultural land, a good land management planning should be prepared and then implemented with transparent policy.

According to the Phnom Penh Post published on December 2013, the forest coverage in Cambodia has drastically declined from $60.18 \%$ in 2009 to $40.33 \%$ in 2013. On the other hand, in Preah Vihear, forest cover was diminished to $-17.9 \%{ }^{1}$ from $1996 / 97$ to $2012^{10)}$. The forest resources play two major roles in Preah Vihear. The first role is to prove important ecological functions: ecosystem preservation, biodiversity conservation, and the protection of soil and water reources ${ }^{11)}$. The second one is to significantly contribute to the socioeconomic development of the country. The collection of forest productions is the second most important factor to livelihoods. For example, resin tapping in most of households is their key secondary

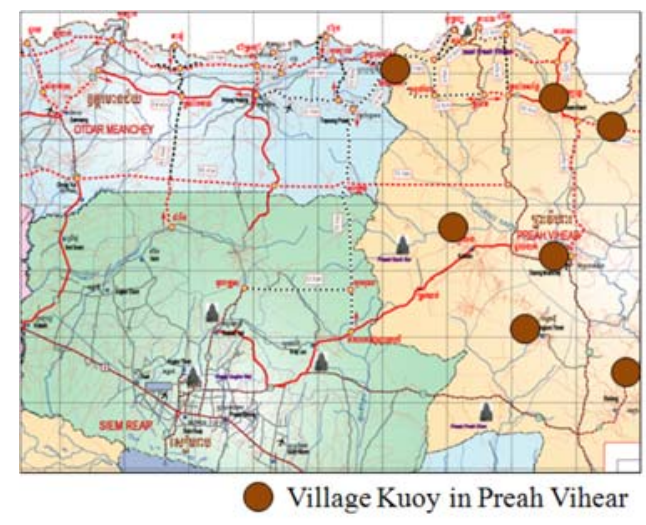

Fig. 9 Map of vallage Kuoy in Preah Vihear ${ }^{3)}$

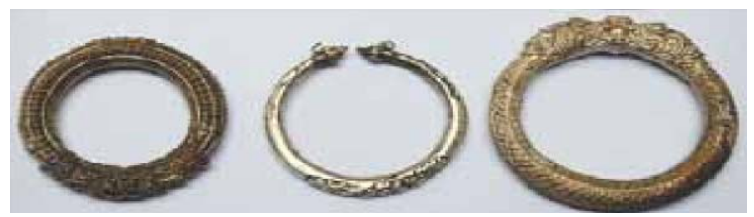

Fig. 10 Examples of traditional jewelries

occupation because of its importance for cash income $^{12)}$.

Unfortunely forest resources are depleting progressively in Preah Vihrear region during the last four years. For example, intensive cut was caused by illegal logging and concession to big timber exploitation companies such as Cherda Plywwod, Chung Shing North,Lan Song Preah Vhear companies $^{13)}$. In many ways, forest products are essential to support diversity of industries. The applied products range widely from construction material such as timber to household items such as furniture.

\section{c) Diversity and Immaterial Value}

Preah Vihear disposes of a rich diversity of living cultural heritage. The tradition, the way of life and the social value with its qualities and defaults constitute a rich human ethnological variety. The Kouy population shown by Fig 9 was dominant in the area and it is believed to be part of the early settlements in the Dangrek Mountain range with their skill in iron smelting that led to the mass production of arms for Khmer army. Ceramic, bronze, silver and pottery work as well as elephant hunting were part of their livelihoods such as those shown by Fig.10.

Many ethnic groups still practice the traditional way of life and use their own language. Classified as austro-asian, the Kuoy population is found in the Preah Vihear province. They selected their habitat in high ground and up to the mountains living close to 
nature on which they rely for their everyday needs for livelihoods.

The minority ethnics in Cambodia, as shown by Fig.11, have become an essential element in the process of cultural development. They are of intangible values which have valuable contribution to the freedom of expression and the right to preserve human identity and individuality which are the potential source of humankind creativity.

Foods and cuisine are also part of Khmer culture since they have origin in the traditional way of long and studious preparation with the use of natural ingredients. Khmer cuisine, national and local, has a hierarchy; it ranges from the ordinary population and ends to the royal family. This aspect of culture can be promoted as tourist product.

\section{d) Artistic Value}

The interrelation between cultural diversity and a broad spectrum of human activities enhances cultural productivity through the commercialization of cultural expression. It gave the broader impacts on business and the marketplace. The creative impulse is considered as the root of cultural diversity. In fact, it nourishes innovative response in a rapidly evolving environment. In this sense, artistic creation (painting, dances, folklore, theatre, traditional sports, etc.) and all forms of innovation may be primary imaginative sources of cultural diversity for many centuries.

Handicraft is considered as tangible and positive aspect of the participation of cultural diversity in direct economic development, by giving artistic tone to decorative or domestic objects.

Mass production of handicraft, which comes through industrialization process, has a tendency to lose its genuine quality. Therefore that might diminish its creative value created by individual talent or freedom of expression. The flooding of traditional markets with industrial products had a serious impact on craft economies. To avoid this phenomenon, policy should be required to ensure fair returns on handcraft products of equal quality. At the same time, it preserves the traditional knowledge.

\section{e) Man-made Landscape and Nature}

Man living with its natural environment in the region of Preah Vihear is continuing for centuries without drastic changes or brutal transformation of natural milieu. The process of symbiosis that happens between man and nature is still kept in a good balance. The cycle of eco-system has not yet been disrupted, but if there is no protection program designed to preserve it, the disequilibrium of the whole mechanism of natural recycling of species, fauna and flora could be in danger in the near future.

Along with existing natural landscape, the Khmer people have created an environment that is well harmonized in the milieu of their habitat. This is due to the requirements of the livelihoods that force the people to modulate nature to accommodate their living conditions. The land for agriculture as well as the forest nearby is the primary resources for the Cambodian people for many centuries.

Many other man-made landscapes can be considered as results of wealth from nature, because the combination of natural elements combines with the everyday life activities of the farmers. One can find a typical example of Cambodian landscape in rice fields. It represents a diversity of rural aspects at every season of the year. Farmers work in rice field with their traditional tools and help domestic animals.

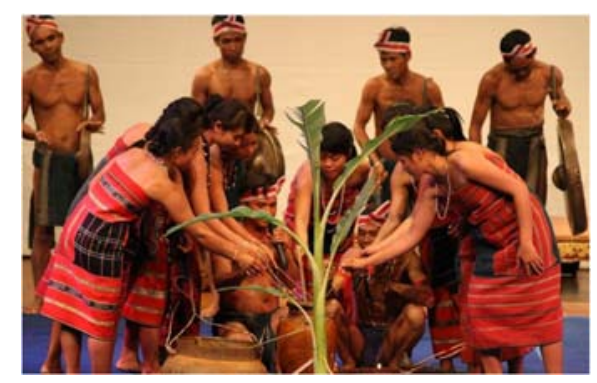

Fig.11 Minority ethnic traditional dance for weeding (Curtsey of Ministry of Tourism 2007)
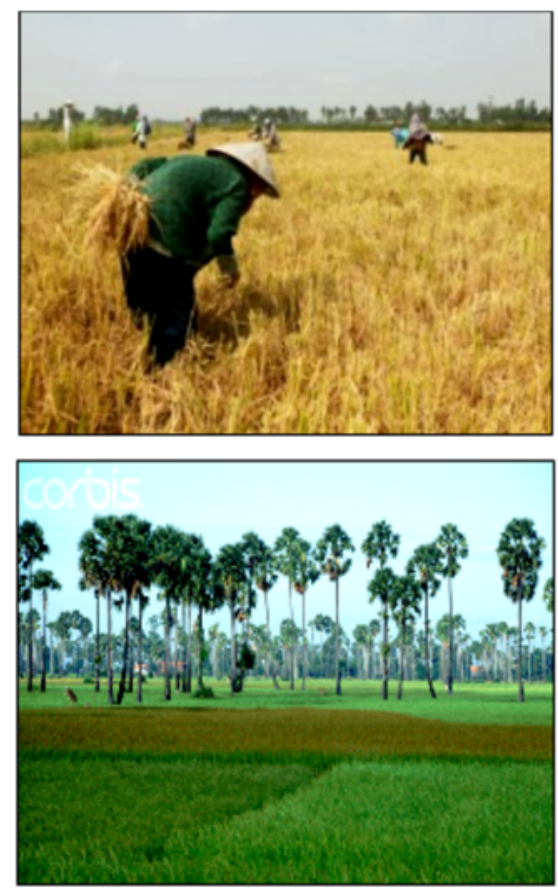

Fig 12 Typical landscape in rural area 
In the rain of the monsoon seasons, they sow the paddy seed. That shows the harmonious relationship between nature and man activity. The field turns yellow-green when the rice is blooming; the crowd of people participates in harvest by singing or playing flutes. That's a picturesque scene of happiness. And aftermath, the field changes its color into light brown. The change is a sign for the end of the paddy production process in the year. The sequence of this cycle of colors combines with the labor of farmers. It marks the end of seasons. The scene of joyful festival appears in a rural landscape as shown by Fig.12.

\section{f) Social and Traditional Value}

Social and traditional value can also be considered as wealth taking in its wide sense of definition. The belief of the people in its traditional and social everyday life, the diversity of ways of living comprising those of minority ethnics and languages are all parts of intangible wealth. The wedding and religious ceremonies, the local gastronomy, the New Year celebration, local music and dances are parts of social and traditional values as shown by Fig.13.

Many tourists especially young people, who wish to understand the deep root of Khmer culture, are now interested in going to rural villages and spend their weekend with farmer's family by sharing simply bed and breakfast.

From that point of view, social and traditional
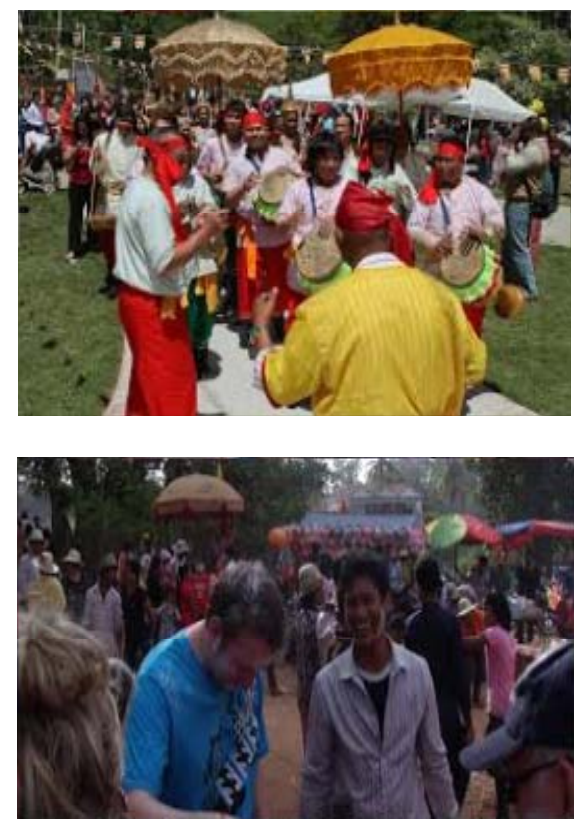

Fig.13 Cambodian New Year in a village

(Khmerization.blogspot.com \&commons.wikimedia.org) values represent, therefore, an invaluable capital capable in transforming itself into investment assets. These assets in turn would yield produced capital, transaction collateral or equity that can be used for commercial negotiation. Compared to the whole nation, Preah Vihear wealth is modest. Nevertheless, at the scale of remote and undeveloped area, it constitutes an important endowment of the World Heritage site and its region.

Up to today, despite many successive dark periods of its history, Cambodia still disposes of many resources, some of which are still undiscovered and many other have been unfortunately mismanaged in different ways, but somehow the available potentials are not all depleted. With a sound policy guideline, the government can still undertake and correct the development reform program. In addition, with the good management by using all kinds of existing and available resources, the World Heritage Site of Preah Vihear could become an engine to reduce the unbalanced development between the cities and this region, which is one of the isolated and poorest of the country.

It should be precisely judged that taking opportunity of this moment mobilizes the national rise of concern and interest of the local people. The government should seek to see how the potentials of Preah Vihear is used and optimized. As the long-term vision fosters a practical development scheme, people transform this undeveloped area into a place where poverty gap could be reduced and economic activities could take place. In engaging a new development initiative, there is hope for better living conditions of the poor population who were suffering under the Khmer Rouge's regime.

\section{TOURISM AS MOTOR FOR DEVELOPMENT}

\section{(1) Before Inscription as a World Heritage}

The judgment of the International Court of Justice (ICG) of Hague in 1962 declared that Preah Vihear belonged to Cambodia, and this decision has made Cambodia pay more attention to the importance of the temple. After the fall of the Khmer Rouge's regime and the declaration of national unity for the country, the historic temple revealed its significant cultural value and its economic potentials. 
Before the border dispute between Thailand and Cambodia, the number of tourists was already increasing steadily. Many came from Thai border and only a few acceded from Cambodian side. The reason is why Thailand has a good access road and better transport service in its territory. Furthermore, the professional travel agencies assist tourism by good advertisement campaign. Therefore, tourism activity had already taken place; even the site was not yet internationally recognized and listed as a World Heritage monument. It has been estimated that Thailand had benefit from Preah Vihear temple for a number of years, because of increasing tourism revenue. On the other hands, on Cambodian side, a spillover effect caused by the number of tourists from Thailand was observed by an intensive activity of border market operated by peasants who live around the site of Preah Vihear. At present, the revenue from tourism is still negligible ${ }^{13)}$.

\section{(2) Understanding of the Value}

The dispute between the two countries from 2007 gave the opportunity to Cambodia to understand the cultural value and the economic potentials of Preah Vihear in terms of resource generator, particularly in the tourism sector. Since then, many road infrastructures have been constructed and facilities have been created in order to provide visitors better access to the World Heritage Site. Responding to the government efforts, a rapid development of local

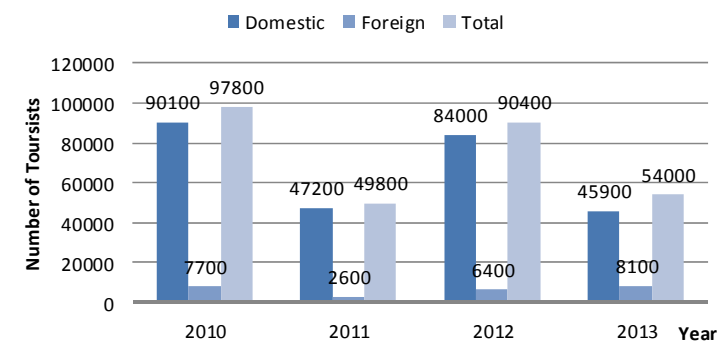

Fig.14 Tourist number visiting Preah Vihear temple at the same period of the year (Feb. to Nov.) ${ }^{14)}$

Table1 Fluctuation of tourists between 2010 to $2013^{14)}$

\begin{tabular}{|l|c|c|c|}
\hline Tourist & 2011 & 2012 & 2013 \\
\hline Domestic & $-47.6 \%$ & $78.0 \%$ & $-45.4 \%$ \\
\hline Foreign & $-66.2 \%$ & $146.2 \%$ & $26.6 \%$ \\
\hline Total & $-49.1 \%$ & $81.5 \%$ & $-40.3 \%$ \\
\hline
\end{tabular}

tourism has started at the scale of the nation mainly due to the feeling of nationalism by the great majority of Cambodian population motivated by patriotism and pride of their culture. At the same time, the local phenomena have stimulated the curiosity of foreign visitors to wish to comprehend the political issue emerged from the World Heritage Site highlighted by serious dispute (successive arms clashes) between Thailand and Cambodia. Since the political conflict started and with the help of mass media, foreign tourists started to come visiting Preah Vihear to discover the universal cultural value of the temple. Until 2009, the number of tourists to this region had been negligibly small. According to the director of the Department of tourism of PVNA, Mr. Kong Vibol ${ }^{14)}$, this trend of visitors has been growing dramatically since 2010 and continuing up to the present time with a peak period in 2012 as shown by Fig.14. But despite the increase of tourists, PVNA has yet to improve the quality and the facility on the site. Efforts to preserve the temple and to provide efficient in maintenance work is becoming a priority.

Table 1 gives the percentage of up and down of the number of tourists visiting Preah Vihear temple compared to the previous year at the same period. The drop of tourism number in 2011 and 2013 is due to bad weather (2011 and 2013 flood), and fear of arm clash with Thailand after ruling of International Court of Justice on the contentious land around Preah Vihear temple. While the increase of tourist number in 2012 is due to good access roads from Siem Reap and from other provinces close to Preah Vihear site.

The massive rise of number of tourists has opened the way to migration of people from other areas in the particularly poor and remote regions. Some people do not dispose any more land and try to survive by looking for work. To cope with the problem, infrastructure projects and social support measures have been undertaken to facilitate the population settling down in the region. Market has become a daily commercial exchange place. These facts show that the temple of Preah Vihear has proved that potentials do really exist and that the World Heritage Site is able to pave the road for the development.

\section{(3) Tourism as a Prior Application}

The first and immediate field of application is so far the tourism. From this sector, it would not be 
difficult to foresee other connecting segments of development. Tourism, if well planned, would draw direct effects on the other components of related activities. These activities can start to fulfill immediate necessities such as hotels, guesthouses, restaurants, souvenirs shops, transport systems that directly support the momentum of the tourism industry.

Many secondary and/or indirect economic segments would be triggered such as amenities, services, and jobs creation to accompany the main structure of tourism growth. Therefore, in visualizing the perspective of this spearhead of development initiated and led by tourism potentials, Preah Vihear is able, in this context, to play the role as the motor of the economic growth and social improvement in the future.

\section{(4) Strategy and Policy}

Considering the immediate available potentials of Preah Vihear and its region, the development in the sector of tourism could take its root in two main sources. The first is undoubtedly the rich cultural heritage and the second the natural environment within its eco-system.

Since tourism industry is becoming a popular sector of economy that is sometimes difficult to control and appreciate its real value, it would be wise that the sound strategy is sought off before any orientation is adapted and inappropriate actions are implemented. Strategy to be conceived and policy to be designed should take into consideration the development of tourism in other countries of the region. Thailand, Malaysia, Singapore are the countries which rely also on tourism industry to push forward their economic growth. Compared to Cambodia, these nations for many years have solid experiences in the management of their tourism resources. They are capable of initiating new ideas, and therefore create new tourism products. In terms of infrastructures, quality of services and tourism network, they are well operational to attract visitors, and in terms of products, they have diversified and are able to use their resources in making tourism one of the components of their development. In addition, they could optimize their natural elements such as beaches, mountains, forest to integrate with the climate to provide visitors all year around a popular tourist destination.

At the scale of the country, Cambodia has practically the same potentials as those neighbors but falling behind them because of internal political problems, lack of human resource and absence of a good vision of tourism development. In the context of hard competition from countries in the region, the Cambodian tourism needs a new approach to formulate a policy framework in order to have a better chance to challenge the neighbors. However, far more than their riparian rival countries, Cambodia benefits from invaluable cultural assets such as archeological sites, famous temples such as Preah Vihear World Heritage Site and immaterial heritage, of great value like royal ballet, religious festivals. These advantages allow Cambodia to be in position to challenge other touristic destinations in the region.

Drawing up a tourism road map based on authenticity, singularity and local specificity of the country or region seems to be an effective solution. Looking through that angle, the cultural and natural tourism should be the main aspiration because it would have different aspect. It reflects the identity of the country and by the same time avoids aggressive competition from the countries in the region that have, for many years, given priority to the tourism of leisure.

Tourism also provides access to the diversity of cultures in their natural setting, which illustrates the tension between authenticity and commercialization that is central to the preservation and promotion of cultural diversity. Now, tourism plays an important role in combining profit-making initiatives with the promotion on intercultural dialogue. Now renewal tourism concept has been observed; its trend is in search of authenticity, which is motivated by the desire to discover other people in their natural, social and cultural cradle. This segment of tourism can compete in the market by the designing of new strategy.

Work plan and strategic planning along the option of this category of tourism needs to be laid out and then be implemented in coherent within the overall scope of available resources. Networks of information should be created to attract potential visitors; facilities to satisfy at international standards, infrastructure provided and safety ensured.

\section{(5) The Sequences of Development}

As shown by Fig.15, the development could first take within the temple area site called $Z_{1}$ because of 
existing infrastructure and facilities created or in the process of being implemented. The second phase of development would be at the areas adjacent to the buffer or protection zone called $Z_{2}$ regulated by the World Heritage Committee. Eco-tourism could be included in this zone providing it will not damage the temple site. The next step to forecast at mid or longterm period would be at the regional level including the space enveloping the World Heritage site at a large scale.

The village of Sraem, which is the main entrance to Preah Vihear temple, should be part of the first phase of development. This small village was an insignificant traveler's stop over for coffee shop before the inscription of Preah Vihear Site into the World heritage list. Now it is becoming a small junction town on the road to the temple and to the capital of province. With rapid increase in population and growth in size, it should be planned - to avoid uncontrolled urbanization that could lead to problematic of land rising cost and ownership dispute. Adequate amenities, high degree of cleanness, and good sanitary conditions are required so the dominant existing market village would transform itself into the gateway to the famous World Heritage site.

Parallel to the above action, tourism plan should be conceived within the scope of regional vision. With the important wealth consisted of many rich archeological sites and monuments, the planners should take advantage of this cultural capital to diversify the products that could be offered to domestic people as well as to foreign visitors. In including regional concept in planning tourism in Preah Vihear, planners could take the opportunity to link the World Heritage site to many other important historic temples built during 10th to 12th centuries among which figure the famous and well-known

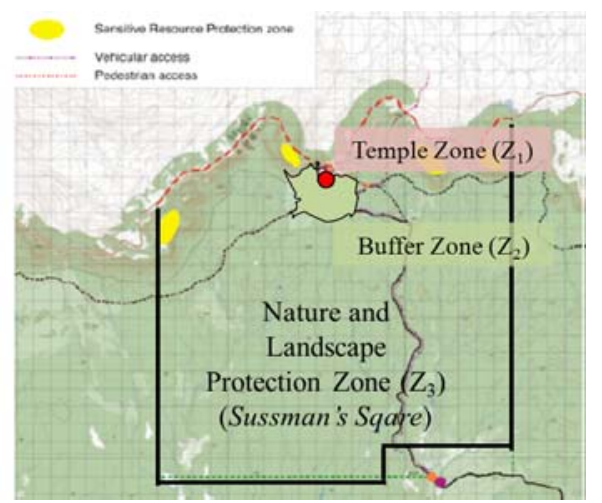

Fig.15 World Heritage Zones and Protection Zone ${ }^{14), 15)}$
Angkor City of the Khmer Empire. This will be interesting for tourist's travel itinerary.

\section{RESOURCE RECYCLING CONCEPT}

Sustainable development depends on the availability of resources and how they are managed. The resources could be of natural resources or of human resources and in most favorable cases they could be of both. The development mechanism can take place in two main categories of countries. The first are the countries that do not dispose of natural resources, but have succeeded in development.

Japan, Singapore, Switzerland, among others are striking examples of countries disposing limited or no natural wealth but succeeding in relying mainly on human resources to achieve their development. These kinds of resources are undergoing a process of continuous recycling to improve their knowledge in technology and in new method of management.

On the contrary, many other countries in the world with important natural wealth but unfortunately they are still in the process of getting out of undeveloped state and sometimes are striking for reasonable living conditions. The reason for this gap of development could have origin in many different ways from environment to human behavior or to the choice of development model.

\section{(1) Case of Preah Vihear}

Compared to the examples in the above paragraph, Preah Vihear is ranged between the two extreme cases. Its cultural and natural resources are sufficient in terms of quantity and quality. It enables the development of the region to be relatively sustainable. At a glance of appraisal of global potentials in Preah Vihear temple in the previous paragraphs, we now know that the available resources do exist and sufficiently allows World Heritage Site to foster regional developments in Preah Vihear and its surrounding areas.

\section{(2) Recycling of Human Resources}

We can find a plenty of good examples in the case study of Japan, Singapore, and Switzerland just to enumerate a few. They let us know how to use human resources to reach sustainable development. It is evident that these developed countries have made tremendous efforts and sacrifice to challenge 
the difficulty of economic environment. Therefore the countries could finally enjoy good performance of GDP growth and attain a relatively high standard of well-being.

If such a growth would be difficult for Preah Vihear so far, it is possible to achieve the same degree of development like that of advanced and developed countries. At least with the lessons from models of development, Preah Vihear can make an appraisal of its chance how to make its development sustainable. With steady average rate of population growth of 1.54 per annum $^{8)}$ and a poverty rate of $29.1 \%{ }^{13)}$, the situation requires tremendous efforts by all stakeholders to overcome the difficulties. Around Preah Vihear site, the communes of Sra Em and Kantuout have a population of 19,402 inhabitants with high illiteracy rate including high migration from poor provinces attracted by the tourism activities which has been exposed of a very limited human resources ${ }^{5}$.

Since there is no program of training and recycling of skilled labor force, a shortage of work is getting serious. As a lack of labor keeps pace with modern technology, new management knowledge is required to build up a solid base for development. The work force, which now exists in the whole country, lacks of experiences in different fields of labor. It would be difficult to remain in this situation and ensure high quality of work and productivity, even if they would respond favorably to the market demand. In this perspective, the inefficiency and incapability in incompetent human resources will make a sustainable development problematic.

In the case of Preah Vihear, at the moment, to rely on tourism alone to spearhead the development of the region, with inadequate in services such as hotels, restaurant staff, information network, travel agencies, public security, and urgent medical intervention are major handicaps. They, as first priorities, should be implemented to respond to that segment of development. The employed personals in tourism industry should be trained and go through periodically recycling process in order to meet obligation as claimed by the competitiveness in terms of production and performance. Providing continuous training to improve quality of labor will ensure the sustainability of human resources needed to maintain the momentum of development.

Along the line of this process, it requires a set of institutions capable of good management of human wealth. Institutional value, governance policy and private sectors are vital for engaging and conducting the approach of upgrading and recycling of human resources. A good cooperation between government at all levels, private sectors and stakeholders have an important role to play in the transformation of primary labor force into skilled workers capable of meeting the demand of different work categories. Nowadays, in Cambodia and particularly in remote area such as Preah Vihear, unqualified workers are abundant and employed at cheap wage in every sector of activities mainly in services and technology. The basic requirements of good quality of services for tourism industry at the standard of international practice are yet to come.

\section{(3) Recycling of Natural Resources}

There are many countries in the world, which dispose great potentials for the development. Somehow, maybe for political reason, human behavior and mismanagement or for other unknown purposes, they have drained out intensively their wealth for many decades. However, it is surprising that they have not proved yet that their development has taken the road for sustainable development. While the target of improving living conditions of the people has not been reached, the natural wealth continues progressively to deplete at the increasing pace. This failure of resources transformation can lead inevitably to exhaust of the available potentials. In that case, resources provided by nature, due to broken reproduction cycle provoked by over exploitation, are unable to regenerate. This happens in mineral resources, forestry, water and agricultural land. These resources constitute the basic elements of nature on which life depends. It has been observed that number of countries in the developing world have overlooked this reality, taking for granted that resources, no matter how, can be automatically selfregenerating or hoping to discover new ones in the future.

For decades, Cambodia has been at risk of forest destruction. For example, to prevent flooding, the government are re-routing waterways and filling existing lakes as natural water regulators. These developments are involved with the process of destruction of natural wealth.

\section{(4) Recycling of Forest}

Forest constitutes a vital natural resource for 
Cambodia. The majority of population more than eighty percent of the total in Cambodia is farmers. The more marginal they are, the more their livelihoods depend on the agriculture and forest. They collect everything they need from the forest. In this respect, forest is considered as a basic and primary resource for human life.

The forest outputs are diverse once renewal through its natural mechanism so to ensure the perennity of the ecological system. It can support life of farmers in a sustainable manner. Unfortunately forest resource is depleting progressively ${ }^{13)}$ in Cambodia, including Preah Vihear region ${ }^{11}$, because of intensive cut most of the time accelerating illegal logging that leads undoubtedly to the destruction of forest. The outlook is pessimistic and the future of this natural resource is uncertain. Preserving forest is a long-range action to ensure the sustainability that is necessary to reach sustainable development. Therefore, the recycling of forest is urgent because forest products are essential to support livelihoods of marginal population and at the same time contribute to minimize the negative effects of climate change.

In terms of total capital wealth, Preah Vihear disposes two important capitals: the natural and the cultural. These are probably combined with intangible and immaterial resources to set up a dynamic momentum of wealth. By doing so, Preah Vihear and its surrounding regions could turn into the road led to sustainable economic and social development.

\section{CONCLUSION}

Preah Vihear can be an engine for the development of the region, if once its potentials of cultural heritage combine with its natural resources. These two major resources have root from the Khmer civilization and gift of nature. Geographical, religious, architectural and landscape features increase the possibility of the region. That will establish the authenticity of capital assets when they can bind together to spearhead the development.

The idea and concept illustrated in this paper indicate that Preah Vihear and its region generate development if their potentials and resources are fully distributed and managed. It could lead to the road of sustainability, if once all the criteria for economic growth works well and conditions for social progress are fulfilled. When tourism is firmly defined as cultural and economic backbone, further steps will appear. In that perspective, Preah Vihear must have a chance to achieve its final goal and reduce poverty gap by sustainable development.

\section{REFERENCES}

1) Someth, UK., Minagawa, M. : Past development and present issues of world heritage region of Preah Vihear in Cambodia, Journal of Construction Management and Engineering(F4), Japan Society of Civil Engineers)Vol.69, No.4, I_313-I_322, 2013.12.

2) The University of Texas Library : Perry-Castañeda Library Map Collection, Cambodia Maps (http://www.lib.utexas.edu/maps/cambodia), 1997

3) Sahay, S. : Preah Vihear; An Introduction to World Heritage Monument (IWSPV), 2009.

4) Council of Ministers : The Temple of Preah Vihear, Kingdom of Cambodia, May 2010.

5) Government of Cambodia : Site sacré du Temple de Preah Vihear : Dossier Relatif à la Mise en Oeuvre de la Décision 31 COM 8,24 Rev du Comité de Patrimoine Mondial (31ème session 2007, Christchurch, Nouvelle Zélande), pp.2-6, pp.10-14, pp.17-28, 2008.

6) Rithy, I., Darith, E., Than, H., Chan, K., Tech, S., Samnang, K., and LARP : Angkorian Infrastructure Development, A Case Study of Living Angkor Road Project, 2008.

7) Department of survey PVNA : Demographic Data in Kantuot and Sra Em communes in Preah Vihear, 2012.

8) Phoeun, C. : List of Temples and Archeological Sites in Cambodia, 2005.

9) Ministry of Planning, Government of Cambodia : Statistical Yearbook of Cambodia (SYBC), 2008.

10) Department of Preah Vihear National Authority : Tourism 2012, Phnon Penh Post, 14 Dec. 2013.

11) Cambodian Development Research Institute /Wild Life Conservation Society (CDRI/WCS), 2008.

12) Cambodian Development Research Institute (CDRI) : Wildlife Conservation Society, Focusing on Cambodia's High Value Forests: Livelihoods and Management, 2004.

13) The Atlas of Cambodia; National Poverty and Environment Maps, 2006.

14) Department of Tourism, Preah Vihear National Authority: Static Yearbook of 2008, 2009.

15) Gupta, D., Balen, K.V., Jiang, L., Sussman, R., Llopis, E., Shimizu, S., Beschaouch, A., Peou, H., and Phoeun, C. : Dossier Relatif à la Mise en Oeuvre de la Décision du Comité de Patrimoine Mondiale, 2008. (32ème session2007, Québec, Canada).

(Received May 19, 2014) 